\title{
El modelo económico en Viaje a las Estrellas (Star Trek)
}

doi: 10.52749/fh.v2i3.4



\section{HANS ROTHGIESSER}

Economista de la Universidad del Pacífico con maestría en periodismo por la Universidad de Gales (Reino Unido). Ha publicado material en El Comercio, Perú Económico, Perú 21, Semana Económica y otros medios. Ha enseñado en la Universidad del Pacífico, en la Universidad Nacional Mayor de San Marcos, la Universidad Peruana de Ciencias Aplicadas, en la Universidad de Lima y en la Escuela de Edición de Lima. Actualmente es miembro del consejo consultivo del Grupo Stakeholders, conduce el podcast Nación Combi y el podcast de economía Marginal para RPP, escribe quincenalmente para eBiz Noticias y para El Reporte.

\section{http://mildemonios.pe/ $\because$ @mildemonios}

Resumen. El mundo representado en las series y películas de la franquicia Star Trek trasciende muchas de las reglas que tenemos hoy en día para la sociedad como la conocemos. En ese sentido y como consecuencia de las distintas tecnologías avanzadas que presenta, ¿está ese mundo más allá de las reglas de la economía moderna como la entendemos hoy? A partir del análisis del impacto de dos tecnologías existentes dentro del universo narrativo de la franquicia (uno ofrece un bien y el otro un servicio) llegamos a la conclusión de que las reglas básicas de la microeconomía convencional se aplican en el futuro representado.

Palabras clave: ciencia ficción, economía, tecnologías, Star Trek, Viaje a las Estrellas

\section{Introducción}

La franquicia Star Trek está compuesta de series, películas y novelas. Si bien representan una sociedad del futuro, ésta está imaginada por guionistas y creadores del presente, que proyectan lo que conocen hoy en día. De esa manera, cuando introducen tecnología que no existe aún, se la imaginan usando elementos modernos. Lo mismo pasa con el impacto que tiene esa tecnología en la sociedad de ese mundo futurista. En ese sentido, ¿qué pasa con la manera como estas tecnologías afectan a la economía de esta sociedad? ¿Rompe por completo con las reglas de la economía que conocemos hoy o generan nuevas relaciones que no se pueden entender con el conocimiento con el que contamos?

En este documento se va a comentar específicamente dos de estas tecnologías, los cuales en algunos círculos son mencionados como los responsables de la muerte de la economía moderna dentro del universo ficticio de Star Trek. Uno de ellos representaría el final del mercado de los bienes, el replicador; el otro, de los servicios, el holodeck. ¿Es cierto que estas dos tecnologías ponen un final al problema de estudio de fondo de la economía: la escasez?

\section{Qué es ciencia ficción}

Empecemos por definir qué es "ciencia ficción". Este término tiene muchas posibles definiciones. El primer intento data de 1916, cuando Hugo Gernback utilizó el neologismo "scientifiction" para referirse al género que estaba emergiendo en ese momento (Gernback, 1916). La popularidad actual del género ha llevado a lo que Menadue, Giselsson \& Guez, 2020 llaman definiciones populares y definiciones canónicas. Una de las más citadas es la del célebre escritor de ciencia ficción Robert Heinlein, que definió al género en 1947 como "ficción especulativa" (Heinlein, 1991).Ésta usaría ciencia contemporánea aceptada y la extrapolaría para producir nuevas situaciones, las cuales serían exploradas a través de las acciones de los humanos que ahí residen, típicamente resolviendo problemas. Autores más modernos, como Samuel Delany, toman esta definición como una mera referencia histórica y proponen una que incorpora elementos históricos (Delany, 2009), pero que en realidad deja el espacio lo suficientemente abierto como para que el género se vuelva a redefinir. 
Para efectos de este documento, vamos a usar la definición original de Heinlein, con algunos ajustes posteriores. Por ejemplo, Staisnlaw Lem coloca una restricción bastante razonable: que todos los elementos introducidos en una historia de ciencia ficción deben poder ser interpretados de manera empírica o racional. Es decir, que en ciencia ficción no puede haber maravillas inexplicables (Lem et. al. 1973). Esto introduce un elemento subjetivo a la definición. Philip K. Dick, otro autor emblemático de la ciencia ficción, comenta el ejemplo de los mutantes en la obra de Ted Sturgeon (Dick, 1999). A algunos lectores su existencia les podría parecer posible y a otros no, por lo que los tomarán como si estuvieran leyendo sobre hechiceros o dragones. Para los primeros es una historia que se enmarca dentro del género de la ciencia ficción, para los segundos en la fantasía.

No obstante, este elemento subjetivo es útil, porque invita al debate en la audiencia, el cual debería ser lucrativo en la medida en la que ayuda a difundir ciencia, a expandir la exploración científica más allá de los límites de la obra, etc.

\section{Star Trek es ciencia ficción}

Como lo desarrolla Jeremy Berlin para National Geographic, una de las razones por las cuales Star Trek se ha podido mantener vigente por más de medio siglo es por basarse en hechos científicos verdaderos (Berlin, 2016). De hecho, sus trece películas, seis series de televisión y productos mediáticos adicionales (libros, juegos, historietas, etc.) han podido llevar a la ciencia ficción a donde no había ido antes. Un análisis más detallado, como el que hace Andrew Fazekas, revela que los creadores de este material usaron elementos reales de la ciencia contemporánea, los cuales son constantemente mencionados (Fazekas, 2016).

Típicamente en Star Trek los personajes se enfrentan a problemas y los resuelven usualmente utilizando la ciencia extrapolada de ese escenario ficticio. Algunos de estos elementos que comenta Fazekas son: las menciones a cuerpos celestes verdaderos, etapas en la vida de una estrella, los límites del universo, simulación por computadora, etc. Fazeka comenta también que hubo un interés concreto por incluir estos elementos científicos. Esto se ve reflejado en el hecho de que científicos reales fueron consultores de las distintas series de la franquicia. Sus opiniones y aportes fueron incorporados a los guiones de distintos episodios.
Conforme la tecnología y la ciencia avanzaba, se iba introduciendo nuevos elementos a las series, los que permitían cumplir con el requisito de la especulación científica del que habla Heinlein.

Hay un detalle adicional que hace de Star Trek una franquicia particularmente interesante para analizar: es un producto que ha estado presente por más de 50 años. Es bastante interesante, en ese sentido, encontrar documentos que repasan la representación de distintos conceptos en el universo ficticio de estas series y películas. Basilowski et al. (2020) por ejemplo, lo aplican a la representación de los desórdenes psicológicos. De hecho, eso es precisamente lo que se pretende hacer con el presente documento, pero aplicado a conceptos de economía.

\section{Cuál es la preocupación de fondo de la ciencia} económica

Hay distintas definiciones que compiten por expresar cuál es el objeto de estudio final de la economía. Una de estas es la propuesta por Lionel Robbins en 1932: "La economía es la ciencia que estudia el comportamiento humano como una relación entre objetivos y recursos escasos con usos alternativos" (Robbins, 1932). La definición específica de la economía es algo que le preocupó profundamente a Robbins, quien le dedicó años de su vida. Para él, la definición de los objetivos de los agentes económicos no era parte del campo de la economía. Estos eran decididos por autoridades o por la naturaleza humana. La economía se encargaba de la mejor administración de los recursos con los que se cuenta para alcanzar esos objetivos (Backhouse \& Medema, 2008).

Para el presente documento vamos a utilizar la definición de Robbins. Veremos cómo nuevas tecnologías presentadas en las series y películas de Star Trek podrían representar un reto a la vigencia de la economía como ciencia, dado que: 1. Ésta estudia el fenómeno de la escasez. 2. Estamos operando en un universo en el cual aparentemente ya no habría escasez, gracias a estas dos nuevas tecnologías.

\section{Nuevas tecnologías en Star Trek que atentan contra el dilema de la escasez}

Si la escasez es el objeto de estudio de la economía y las nuevas tecnologías presentadas en Star Trek reducen la escasez significativamente, ¿se puede aún hablar de que se aplican las reglas de la economía 
conocidas hoy? ¿O son más bien irrelevante? Para responder a estas preguntas vamos a enfocarnos en dos tecnologías en especial. Una reduce la escasez de bienes y la otra, la de servicios.

1) El replicador. En el mundo ficticio de Star Trek existe esta tecnología que inicialmente servía para sintetizar comida a demanda. En Star Trek: The original series (1966-1969) los productos que son generados por el replicador son cubos de colores, que se supone que contienen todos los nutrientes que los miembros de la tripulación necesitan. En la serie animada (1973-1975), el replicador ya genera comida con su forma original, pero sigue siendo descrito como un producto sintético. Recién en la serie Star Trek: The next generation (1987-1994) se le pone nombre a esta tecnología y se le da mayor protagonismo, siendo mencionada en guiones como elemento de la historia. Por ejemplo, en el episodio Allegiance (décimo octavo de la tercera temporada) se sugiere que otras culturas han usado el replicador para crear seres vivos.

Este elemento existía en estas series, pero nunca fue explorado su aspecto científico. ¿Cómo es que algo así funcionaría? En la siguiente serie en ser producida -que en realidad es una precuela a todas las que ya existían-, Star Trek: Enterprise (2001-2005) se presenta una versión primitiva del replicador, que se explica como un reciclador de desechos que presumiblemente serían reutilizados como comida. No obstante, en una serie anterior, Star Trek: Deep space nine (1993-1999) se indica que mientras haya energía, el replicador podría generar aire respirable para la tripulación, lo que indica que no requiere desechos a ser reciclados para replicar productos.

En otros episodios de Star Trek: The next generation se menciona que se usó el replicador para producir ropa, juguetes y otros objetos para regalo. Es decir, no se limita a replicar comida. Es más, el replicador es usado también como basurero. Objetos son reducidos a energía, la cual es almacenada para ser usada luego para replicar otros productos que son requeridos. No obstante, en la serie Star Trek: Voyager (1995-2001), se introducen varios elementos que no se habían mencionado en series anteriores. En el capítulo Macrocosm (décimo segundo de la tercera temporada) se menciona un gel que hace falta para que el replicador pueda crear objetos.

Entonces, si bien es una tecnología que se introdujo en la primera serie sin brindar mayores detalles de cómo funciona, en las series siguientes se ha ido desarrollando y haciendo más explícita hasta llegar a lo que se explica en Star Trek: Voyager, que es la versión del replicador que usaremos.

2)El holodeck. Si bien el replicador cambia por completo la dinámica de los mercados de provisión de bienes, el holodeck lo hace para los mercados de provisión de servicios. Esta tecnología supuestamente proyecta imágenes holográficas en un ambiente controlado, de tal manera que el usuario pueda tener distintas experiencias preprogramadas.

A diferencia del replicador, el holodeck no apareció en la primera serie, Star Trek: The original series, sino en la segunda, Star Trek: The animated series. Específicamente en el tercer episodio de la segunda temporada. No obstante, en esa ocasión no se llamó holodeck, sino recreation room (en castellano: "cuarto de recreación"). Este elemento ni siquiera es central a la historia; sin embargo, en la siguiente serie, Star Trek: The next generation, la tecnología ya es llamada holodeck y tiene relevancia no solamente central en algunos episodios, sino que además tiene presencia constante a lo largo de las siete temporadas. En esta serie los hologramas del holodeck son tangibles y las inteligencias artificiales de los personajes proyectados son mucho más elaboradas y en ocasiones superiores a la de los usuarios.

El primer episodio de esta serie que se centró en el holodeck fue el décimo segundo de la primera temporada, describe cómo tres de los personajes principales quedan atrapados en una fantasía mientras trataban de relajarse durante una misión diplomática. La fantasía en cuestión recrea un ambiente estereotípico de las películas de gánsteres de Estados Unidos de los años 40. Este recurso sería retomado en múltiples capítulos de esta serie: que personajes por alguna razón se quedarían atrapados en una fantasía recreada en el holodeck. En ese sentido, esta tecnología se convierte en un recurso narrativo muy rico, al mismo tiempo que se convierte dentro de la realidad de la franquicia de Star Trek, en un elemento muy presente en la vida de los personajes.

Es más, eventualmente se le muestra como herramienta de trabajo. En la serie Star Trek: Voyager, ante la falta de un staff médico, se genera un doctor holográfico de inteligencia artificial para que sea el que trate a la tripulación herida o enferma. A lo largo de la serie esta inteligencia artificial desarrolla perso- 
nalidad y se convierte en un personaje más de la serie. En Star Trek: The next generation el holodeck es usado para simular estrategias en el espacio para planear batallas.

Es decir, mientras que en el caso del replicador, hacía falta elegir una versión de la tecnología que se estaría utilizando para analizar, en el caso del holodeck sí hay consistencia a través de las distintas series y películas acerca de sus límites y de su evolución.

¿Representan estas dos tecnologías el fin de la escasez económica?

Se podría especular que la existencia de estas dos tecnologías hace que las teorías convencionales de economía ya no se apliquen en el mundo ficticio de Star Trek. De hecho, esta hipótesis iría de la mano de la intención del creador de esta franquicia, Gene Roddenberry, que buscaba retratar un universo en el que se "use drama y aventura como una forma de representar humanidad en distintas formas y creencias. El resultado fue que Star Trek (...) es una expresión de mis propias creencias usando mis personajes para actuar problemas humanos $y$ ecuaciones" (Alexander, 1991). Roddenberry siempre dejó en claro que su intención era retratar un futuro ideal, en el que no hubiese muchos de los problemas sociales que preocupaban tanto en su época. En ese sentido, ¿no tiene sentido pensar que también pensaba que el futuro sería uno en el que ya no habría escasez de bienes o de servicios, como sí lo tenemos hoy en día?

No obstante, voy a argumentar que ése no es el caso.

El replicador. Efectivamente, en la versión que se muestra en Star Trek: Voyager, es una forma de obtener cualquier objeto que se programe. No obstante, no es una fuente inagotable. Como ya se vio, necesita energía y un material que es transformado. En ese sentido, no es una fuente ilimitada de recursos, sino una fuente relativamente abundante de bienes.

¿Por qué habría productores de cualquier otra cosa, entonces? ¿Por qué hay campesinos, por ejemplo? En un entorno con agentes económicos racionales, se evaluarían dos opciones: producir comida orgánica por la manera tradicional (sembrándola y cultivándola) o activar un replicador. La teoría económica clásica diría que, ante estas dos alternativas, el agente optará por usar la que le represente un mayor beneficio neto, considerando que ambos conllevan costos y beneficios.

Es decir, en la medida en la que el costo de la opción replicador es cada vez menor, como se puede apreciar conforme se avanza en su representación en las series, y los beneficios son cada vez mayores (se pasa de replicar cubos a comidas más elaboradas), el replicador tenderá a ser la opción seleccionada.

No obstante, ¿es cierto que el replicador soluciona el problema de la escasez? No realmente. Como ya hemos visto, se trata de un artefacto que requiere de al menos dos insumos para funcionar. En ese sentido, representa una solución a la escasez relativa, pero aun así está sujeta a las reglas de la escasez. Usar el replicador es una decisión económicamente racional que sigue aplicando las reglas de la economía como la conocemos hoy en día.

Segundo, el holodeck. Como lo vemos en las series, es una fuente de servicios de ilimitadas opciones. Ahí se puede practicar deportes, se puede participar de narraciones interactivas, se puede aprender, etc. Por lo que vemos en Star Trek: Voyager, los usuarios creativos pueden utilizar el holodeck para lo que sea. En ese sentido, estaría reemplazando a los ofertantes de esos mismos servicios en la vida real, dado que ambas opciones son sustitutos casi perfectos.

En teoría microeconómica dos productos pueden ser sustitutos perfectos, pero no necesariamente. Por ejemplo, la mantequilla puede sustituir a la margarina, aunque no sea exactamente lo mismo. En ese caso, serían sustitutos casi perfectos. Para Hal Varian: "dos bienes son sustitutivos perfectos si el consumidor está dispuesto a sustituir uno por otro a una tasa constante. El caso más sencillo es aquel en el que el consumidor está dispuesto a sustituir un bien por otro a una tasa igual a 1"(Varian, 2006). Es decir, lo que define la relación de sustitución es la percepción del consumidor, no el proceso de la producción de ambos productos.

En ese sentido, la experiencia de ir a esquiar en el holodeck es sustituto de pasar por la experiencia real en alguno de los planetas que puedan visitar. Habrá que considerar, entonces, los costos de acceder a ambos servicios. Es decir, el holodeck está limitado por su consumo de energía, el cual puede ser alto y significativo, como se puede deducir de varios episodios de las series. Por ejemplo, en el sexto episodio de la tercera temporada el ingeniero 
en jefe del Enterprise utiliza el holodeck para diseñar una solución técnica a un problema. Sin embargo, su trabajo es interrumpido cuando la energía de la nave se vuelve escasa. Entonces el ingeniero debe trabajar usando medios convencionales. Es decir, debe dejar de usar el servicio holodeck, porque su costo relativo se ha incrementado (seguirlo usando implica dejar de usar otros sistemas de la nave, que se entienden como más prioritarios) y es reemplazado por un sustituto imperfecto.

\section{Entonces, ¿aún se aplica la economía clásica en Star Trek?}

Como estamos viendo, en el universo retratado en las series y películas de Star Trek se aplican las leyes de la economía conocidas hoy en día, como la ley de oferta y demanda, así como el concepto de los bienes sustitutos. Hay un elemento adicional a considerar para poder entender mejor esto.

Lo que se suele ver en estas series y películas transcurre a bordo de una nave espacial o de una estación espacial: la nave USS Enterprise C en Star Trek: The original series y Star Trek: The animated series, la nave USS Enterprise D en Star Trek: The next generation, la estación Deep Space 9 en Star Trek: Deep Space Nine, la nave USS Voyager en Star Trek: Voyager, la nave USS Enterprise NX-01 en Star Trek: Enterprise. Sin embargo, es importante notar que las interacciones que se ven en estas representacio- nes no son las de la vida diaria de un ciudadano común de esa sociedad, pues lo que vemos son las aventuras de oficiales de Starfleet. Es decir, las tripulaciones organizadas para servir en estas naves.

Si bien Starfleet está definida constantemente como una organización científica dedicada a la exploración espacial, en la práctica suele ser representada como una estructura militar. Es más, los personajes principales tienen cargos propios de una: Capitán James T. Kirk, Teniente Hikaru Sulu, Comandante William Riker, etc. Como sea, la discusión acerca de la verdadera naturaleza de Starfleet es un tema aparte. Lo importante es notar que la vida de los miembros de Starfleet es particular y se encuentra entre una organización militar y una comunidad de exploración científica. La vida dentro de las naves y las estaciones espaciales no son representativas de la vida diaria de los ciudadanos promedios de esta nueva sociedad.

No obstante, por todo lo expuesto, podemos asumir que en la comunidad interna de Starfleet por lo menos las leyes de la economía actual sí se aplican. Es curioso notar que Roddenberry, cuando creó la franquicia, buscaba representar lo mejor de la humanidad. En el aspecto económico, por lo menos, representó la economía como la conocemos hoy, pero extrapolada a un futuro con tecnologías nuevas.

\section{Referencias}

Alexander, D. (1991). "Interview: Gene Roddenberry". The Humanist. https://thehumanist.com/features/interviews/humanist-interviewgene-roddenberry 1

Backhouse, R. E., \& Medema, S. G. (2009). Defining economics: the long road to acceptance of the Robbins definition. Economica, 76, 805-820. https://doi.org/10.1111/j.1468-0335.2009.00789.x

Basilowski, M., Schönfeld, B., Esser, S., Jatho, A., Kownatka, M., Signerski-Krieger, J., Esselmann, H., Grabemann, M., Mette, C., Strunz, L., Zimmermann, M., Lajcsak, E., Scherbaum, N., Wiltfang, J., Kis, B., \& Abdel-Hamid, M. (2020). From bones to brain: 50 years of Star Trek and changes in the stigmatization of psychological disorders. Current Psychology, 39(5), 1705-1714. https://doi.org/10.1007/s12144-018-9868-9
Berlin, J. (16 de junio de 2016). "Star Trek is right about almost everything". National Geographic.

https://www. nationalgeographic.com/science/article/star-trekscience-space-astronomy-technology-fazekas.

Delany, S. (2009). The jewel-hinged jaw: Notes on the language of science fiction (Vol. Rev.). Wesleyan University Press.

Dick, P. (1999). The collected stories of Philip K. Dick. Carol.

Fazekas, A. (2016). Star Trek The oficial guide to our universe: The true science behind the starhip voyages. National Geographic.

Gernsback, H. (enero de 1916). Electrical Experimenter

[Presentación en PowerPoint]. Smithsonian libraries. https://library.si.edu/digital-library/book/electricalexperio3gern

Heinlein, R.A. (1991). "On the writing of speculative fiction". En G. Dozois (Ed.), Writing science fiction \& fantasy (pp. 5-11). https://staging.paulrosejr.com/wp-

content/uploads/2016/12/on the writing_of speculative ficiton.pdf 
Lem, S., Rottensteiner, F., Gillespie, B. R., DS, \& RDM. (1973). On the Structural Analysis of Science Fiction. Science fiction studies, 1(1), 26-33. https://www.jstor.org/stable/4238839

Menadue, C., Giselsson, K., \& Guez, D. (2020). An empirical revisión of the definition of science fiction. SAGE Open, 10(4), Artículo 2158244020963057. https://doi.org/10.1177/2158244020963057
Robbins, L. (1932).An essay on the nature and significance of economic science. Macmillan.

Varian, H. (2006).Intermediate microeconomics: A modern approach (7th ed). Antoni Bosch editor.

\section{Cómo citar este artículo:}

Rothgiesser, H. (2021). El modelo económico en Viaje a las Estrellas (Star Trek). Futuro Hoy, 2(3), 24-29. https://doi.org/10.52749/fh.v2i3.4

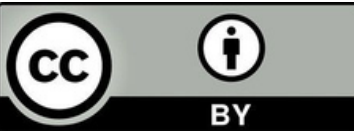

Esta obra está bajo licencia internacional Creative Commons 4.0 Reconocimiento 4.0. 